\title{
Non-surgical periodontal therapy supplemented with systemically administered azithromycin: a systematic review of RCTs
}

\author{
Sabrina L. Buset ${ }^{1} \cdot$ Nicola U. Zitzmann ${ }^{1}$. \\ Roland Weiger $^{1} \cdot$ Clemens Walter $^{1}$
}

Received: 20 January 2015 / Accepted: 24 May 2015 /Published online: 12 June 2015

(C) Springer-Verlag Berlin Heidelberg 2015

\begin{abstract}
Background Azithromycin may be an alternative adjunctive systemic antibiotic in non-surgical periodontal therapy.

Objective This study aims to identify randomized controlled trials evaluating non-surgical periodontal treatment of chronic and/or aggressive periodontitis supplemented with systemically administered azithromycin.

Materials and methods A systematic literature search was performed for publications published by 31 March 2014 using electronic databases and hand search. Randomized controlled trials published in English or German language, with a followup $\geq 6$ months were included. From 231 titles identified, nine publications were eligible for inclusion.

Results Among the studies included, showing some risk of bias, seven reported on patients with chronic periodontitis and two with aggressive periodontitis. Minor adverse events were described in five studies. A synthesis of results using a vote counting method was applied. Significant $(p<0.05)$ beneficial effects of azithromycin were shown in six studies for probing depth changes and in five studies for clinical attachment level changes.

Conclusion In contrast to aggressive periodontitis patients, data from this analysis indicate a potential benefit of systemic azithromycin as adjunctive to non-surgical periodontal therapy in chronic periodontitis patients.
\end{abstract}

Electronic supplementary material The online version of this article (doi:10.1007/s00784-015-1499-z) contains supplementary material, which is available to authorized users.

Clemens Walter

clemens.walter@unibas.ch

1 Department of Periodontology, Endodontology and Cariology, University of Basel, Hebelstrasse 3, CH-4056 Basel, Switzerland
Clinical relevance When contraindications for the standard antibiotics are present, azithromycin (AZM) may be considered as alternative systemically administered antibiotic drug in selected cases of chronic periodontitis.

Keywords Periodontal debridement · Azithromycin . Aggressive periodontitis $\cdot$ Chronic periodontitis

\section{Introduction}

Recent reviews document the benefit of systemic antibiotics as an adjunct to scaling and root planing (SRP), particularly the combination of amoxicillin and metronidazole [1-5]. The combination of metronidazole and amoxicillin is highly active against the suspected bacterial spectrum of the pathogenic periodontal microflora [6-8]. While early reports suggest a synergistic mode of action against Aggregatibacter (Actinobacillus) actinomycetemcomitans (e.g. [9, 10]), recent data show a primarily combinatorial effect $[7,8]$. The combination of the two systemic antibiotics has been frequently prescribed as an integral part in non-surgical therapy for aggressive forms of periodontitis [11-14]. Further, the use of metronidazole plus amoxicillin as an adjunct to SRP in periodontitis patients was suggested in severe chronic periodontitis $(\mathrm{ChP})[15,16]$, in periodontitis among smokers (smokers' periodontitis) $[17,18]$, in severely medically compromised patients [19], in periodontitis associated with the use of bisphosphonates [20], or to reduce the need for further periodontal surgery [21]. In the late $1980 \mathrm{~s}$, the combination of amoxicillin and metronidazole was introduced [22] as an adjunct to SRP in non-surgical periodontal therapy for periodontitis associated with $A$. (A.) actinomycetemcomitans. In this early report, a dosage of $250 \mathrm{mg}$ metronidazole and $375 \mathrm{mg}$ amoxicillin three times a day for 7 days was applied and 
suggested to be administered at the day of instrumentation, e.g. after instrumentation of the last quadrant [2]. Currently, rather different protocols regarding dosage and duration were reported [23-25] for different reasons, including nationally specified administrations or dose adaptation according to body weight of the patient.

However, this adjunctive antibiotic drug application remains a field for controversies [26-29]:

(i) While systemic antibiotics are particularly indicated in combination with subgingival biofilm management, the major concern when administering antibiotic medication is the presence or possible development of antibiotic resistance and/or other severe complications including cardiovascular events [29-31]. Antibiotic resistance increases dramatically worldwide [32], thus highlighting the need for a careful assessment of its indications, duration and dosage.

(ii) In addition, a wide range of adverse drug reactions have been reported for the combination of amoxicillin and metronidazole $[2,33]$.

(iii) Dosage regime and patient's adherence contribute to the effectiveness and resistance of antibiotic agents [34]. In particular, the frequency of intake and duration of amoxicillin prescription $\geq 7$ days led to significantly reduced compliance [35].

Therefore, an ongoing search for suitable alternatives as adjunctive to non-surgical periodontal therapy is reasonable. Recently, a review on azithromycin (AZM), a broad-spectrum, second-generation macrolide, was published [36]. Its promising pharmacokinetic qualities include the uptake in neutrophil granulocytes and fibroblasts, a higher concentration in tissue than in plasma, a slow release at the site of infection and a low incidence of adverse events [37-39]. Its long half-life in plasma $(93 \pm 70 \mathrm{~h})$ and granulocytes $(210 \pm$ $69 \mathrm{~h}$ ) enables single dosages per day and a short administration time [40].

While recent reviews analyzed the effects of systemic antibiotics more broadly and generally [3-5], the specific aim of this systematic review was to evaluate randomized controlled trials (RCTs) analyzing the effect and/or relevant parameters for effect modification of systemically administered AZM as an adjuvant to SRP in non-surgical periodontal therapy.

\section{Methods}

\section{Protocols}

The review was conducted according to the Preferred Reporting Items for Systematic Reviews and Meta-Analyses (PRISMA) criteria [41, 42] (Appendix 1). The research question was explored using the population, intervention, comparison and outcomes (PICO) method.

The specific question addressed was as follows:

In patients suffering from periodontitis $(\mathrm{P})$, does systemically administered AZM adjunctive to SRP during periodontal non-surgical therapy (I) have a beneficial effect on clinical periodontal parameters after $\geq 6$ months of observation $(\mathrm{O})$ compared to SRP with placebo or without adjunctive antibiotic medication $(\mathrm{C})$ ?

\section{Search strategy}

The electronic bibliographic databases MEDLINE, EMBASE and Cochrane Library were searched for citations included as of 31 March 2014. Unpublished reports were identified by searching the OpenGrey (formerly OpenSIGLE) database that lists unpublished literature (http://www.opengrey.eu/). These searches were supplemented by hand searching of pertinent journals. Additionally, potentially relevant citations were harvested from the bibliographies of reports examined for inclusion eligibility. The search protocols within the different databases were applied and validated as identically as possible. Combinations of the validated search terms for MEDLINE/PubMed, EMBASE and Cochrane Library were "periodontal diseases" AND "azithromycin".

\section{Review process}

Two of the authors (SB and CW) screened the titles for potential eligibility according to the inclusion criteria. Based on the abstract screening, 14 studies were selected for full text retrieval and review. Discrepancies in scores allocated to publications were discussed among the authors until a consensus was reached.

\section{Inclusion criteria}

The search was limited to RCTs investigating the effects of systemically administered AZM on non-surgical periodontal therapy. Inclusion criteria were the following: publication in German or English language, human clinical trials, diagnosis of aggressive and/or chronic periodontitis, non-surgical periodontal treatment, systemic administration of AZM, followup of at least 6 months, clinical periodontal outcome parameters [tooth loss, probing depth (PD) and/or clinical attachment level (CAL)] and a control group with non-surgical periodontal treatment with or without placebo.

\section{Exclusion criteria}

Studies were excluded for the following reasons: local AZM administration, surgical periodontal treatment, peri- 
implantitis/peri-mucositis therapy, treatment of gingival overgrowth and reviews or case reports.

\section{Outcome measures}

The primary outcome measure was tooth loss after nonsurgical periodontal treatment supplemented with or without systemically administered AZM. Changes in PD, CAL and minor/major adverse events were evaluated as secondary outcome variables.

\section{Data extraction}

Demographic data, sample size, definition of periodontal disease, measurement of periodontal disease (PD and/or $\mathrm{CAL}$ and recording protocol, i.e. full mouth or partial mouth), definition and description of tobacco use, dosage and administration regime of AZM, minor adverse events (e.g. gastrointestinal tract reactions such as diarrhoea, nausea, abdominal pain or vomiting; peripheral nervous system reactions, such as headache or dizziness [43]) and major adverse events (e.g. hepatotoxicity [44]) and the effect of AZM on clinical periodontal parameters as outcome variables were extracted and summarized in Tables 1, 2 and 3 .

Extent (e.g. localized/generalized; proportion of sites/ teeth affected) and severity (e.g. mild, moderate or severe) of periodontal disease were reported using various summary measures. Effect of adjunctive AZM was expressed as mean $\mathrm{PD}$ or $\mathrm{CAL}$, mean change in $\mathrm{PD}$ or CAL or percentage of teeth with change in $\mathrm{PD}$ or $\mathrm{CAL}$ $\geq 1 \mathrm{~mm}$.

\section{Risk of bias}

The included studies were evaluated using the Cochrane Collaboration's tool for assessing risk of bias [45] (Appendix 2). Considering the adequacy of the reporting in the respective studies, the items were graded and the percentage of positively graded items was calculated [46].

\section{Summary measure}

Due to the pronounced heterogeneity with respect to treatment protocol and outcome measures, as well as variation in study population, sample size and/or statistical methods, a synthesis of the evidence of the included studies using a vote counting method was applied (http://handbook. cochrane.org/chapter_9/9_4_11_use_of_vote_counting for_meta_analysis.htm).

\section{Results}

\section{Study selection}

Initially, 231 titles were identified by electronic and hand searches (Fig. 1). Titles were screened by two reviewers (kappa=0.759). Full text analysis of the 14 potentially eligible reports led to exclusion of five further studies (Appendix 4). Subsequently, nine reports published between 2005 and 2012 fulfilled the inclusion criteria and revealed a moderate to low risk of bias (Appendix 2). In six of the nine studies, $84 \%$ of the possible items (sequence generation, allocation concealment, blinding, incomplete outcome data, selective outcome reporting, other sources of bias) were considered. The remaining three studies valued at least two of six items. Tooth loss was considered as an outcome in one study [48]. All included studies reported on PD and CAL.

\section{Summary of studies: characteristics (PICO)}

\section{Population}

Clinical trials comprised 338 participants with 142 women. Studies included a minimum of 24 [47] up to 92 [48] subjects with mean ages ranging from 20 to 51 years $[47,49]$.

\section{Intervention/comparison}

Two of the nine studies assessed the effect of adjunctive AZM in distinct population groups with respect to the presence of Porphyromonas gingivalis [50] and smoking [51]. From the nine trials included, two investigated a population with aggressive periodontitis (AgP) $[47,52]$. Seven publications considered subjects suffering from ChP [48-51, 53-55]. Fullmouth recording (FMR) using measurements up to six sites per tooth was performed in all studies to assess periodontal disease [47-55] (Appendix 3).

The administration of AZM and the sequence of nonsurgical periodontal therapy varied among the studies. The majority of studies applied quadrant- or sextant-wise SRP weekly or within 2-3 weeks or two to six sessions within 12 weeks. Full-mouth SRP in one visit was applied in two studies [49, 53]. AZM was subscribed at the first [47, 48] or last $[50-52,54,55]$ session or 3 days prior $[49,53]$ to the start of mechanical instrumentation (Table 3).

Seven publications prescribed AZM with a dosage of $500 \mathrm{mg}$ once daily for 3 days [47-50, 52-54]. In one publication, $500 \mathrm{mg} \mathrm{AZM}$ was administered for 5 days [55], and another trial prescribed $500 \mathrm{mg}$ AZM on the first and $250 \mathrm{mg}$ once daily on the 2 nd to the 5 th day [51] (Table 3).

A placebo medication was used in the control groups in five studies [47, 50, 52, 54, 55]. In one study, AZM was compared to further adjunctive antibiotic medications, while 


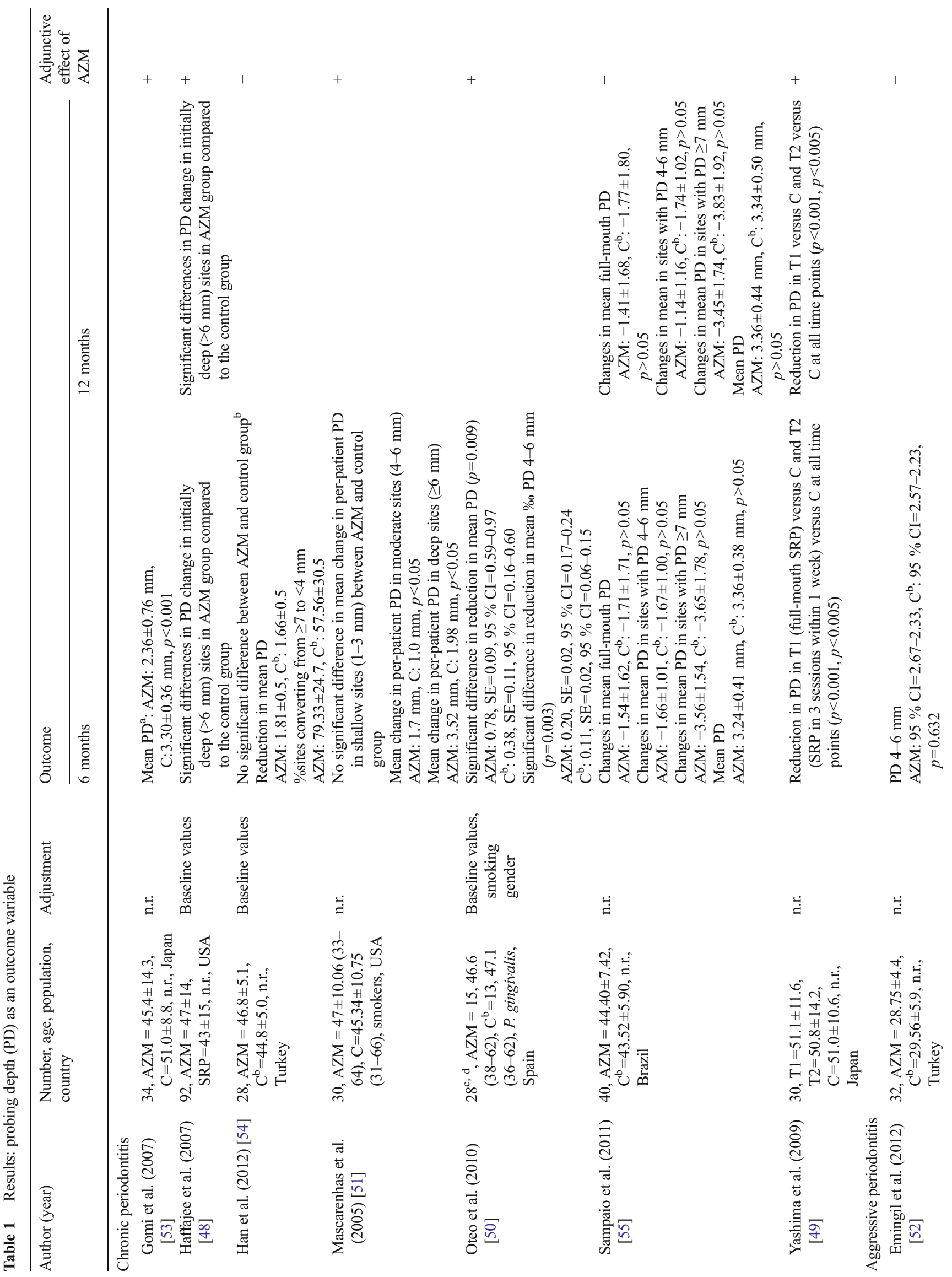




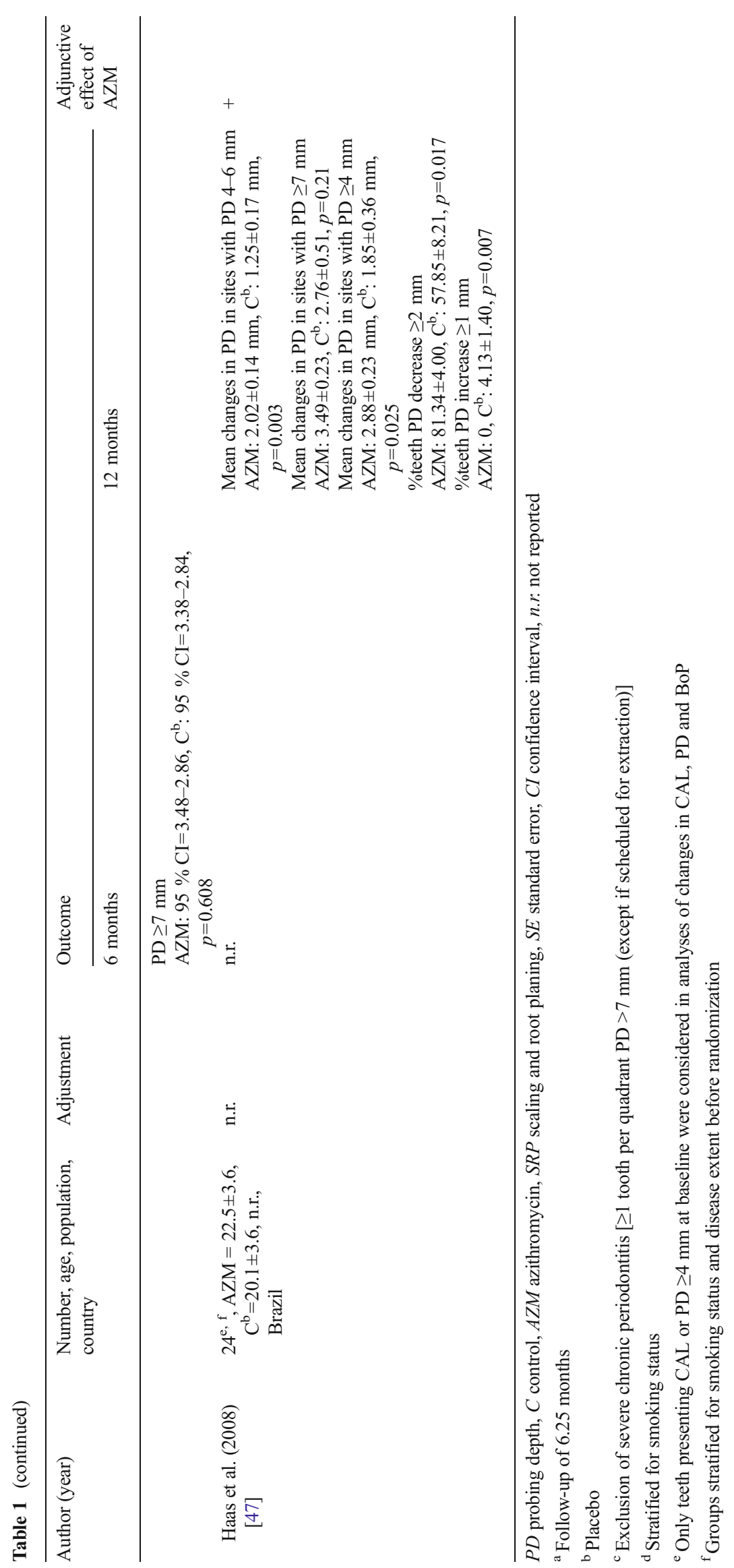




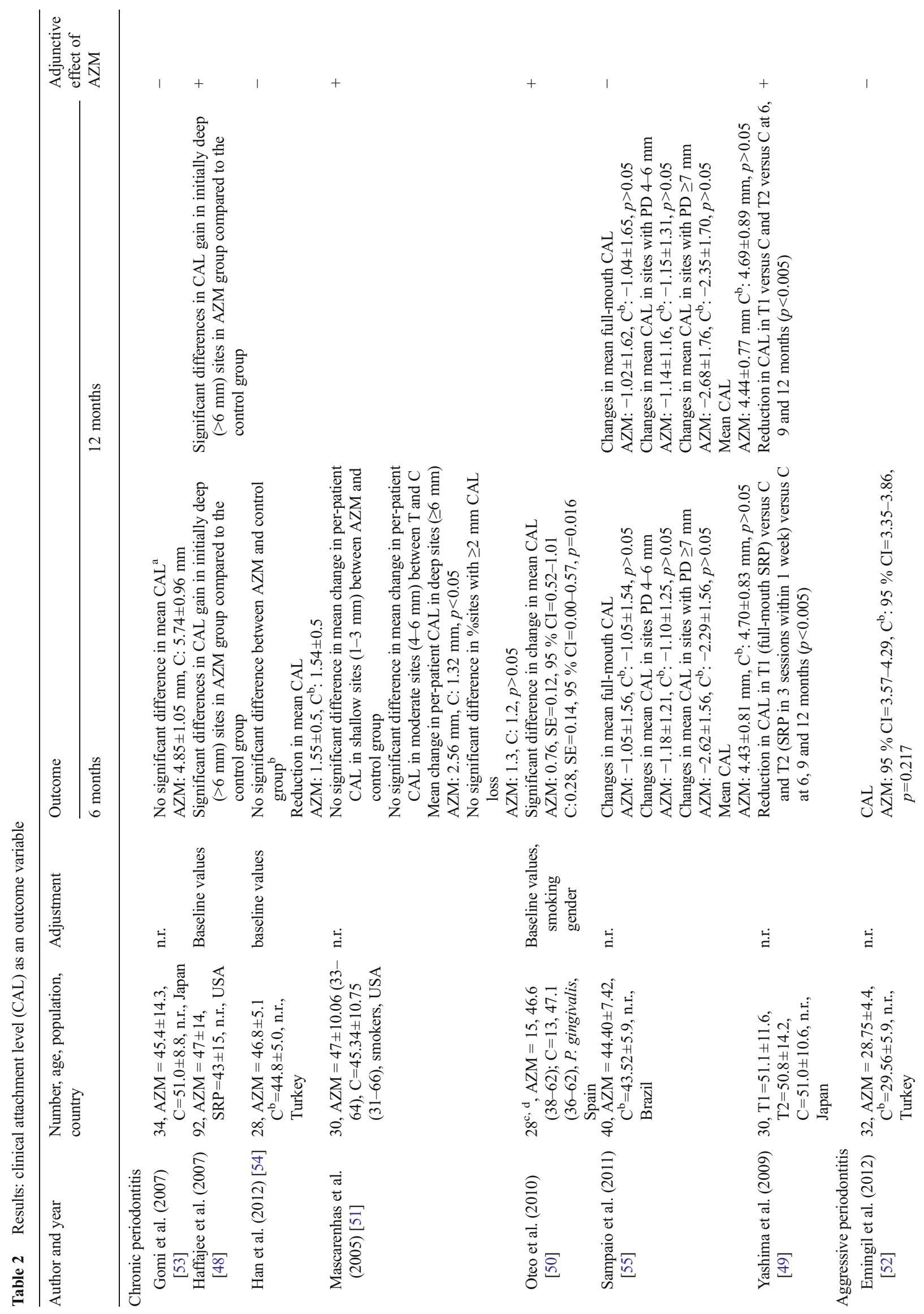




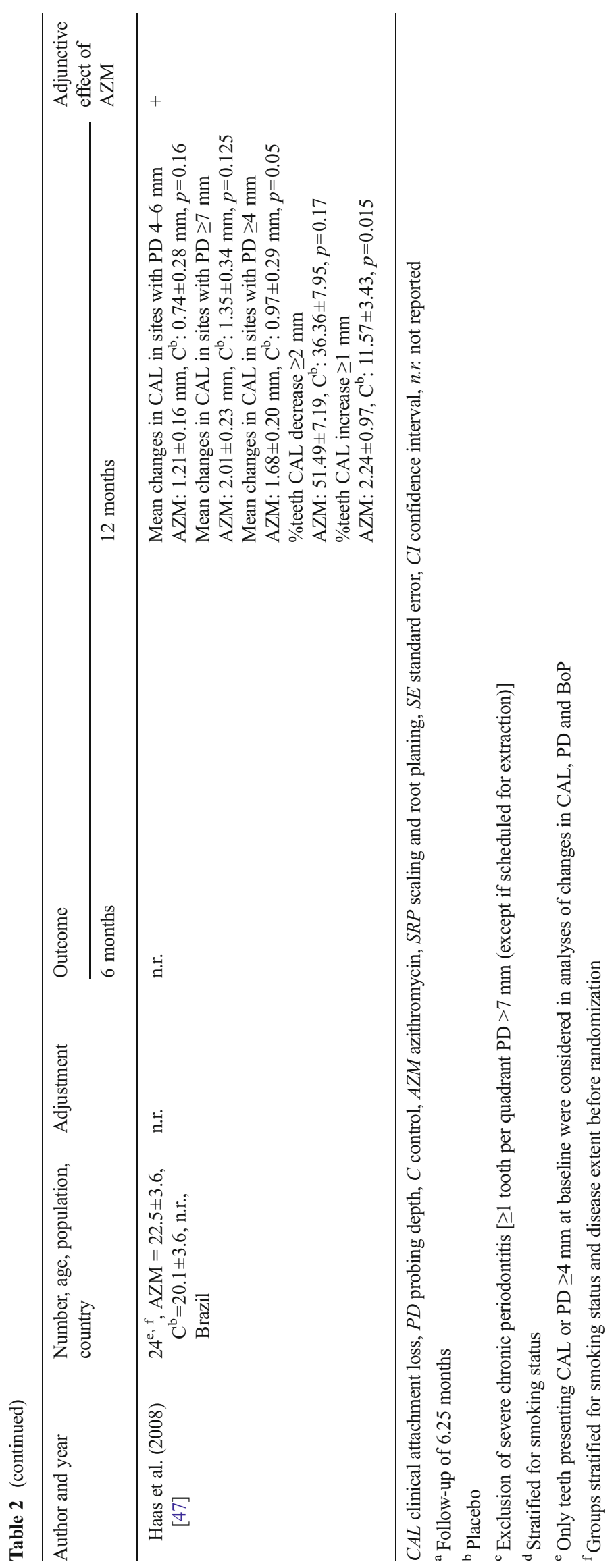


Table 3 Treatment regime, dosage of azithromycin (AZM) and adverse events of included publications

\begin{tabular}{|c|c|c|c|}
\hline & Treatment regime & Dosage of AZM (mg) & Adverse events \\
\hline \multicolumn{4}{|l|}{ Chronic periodontitis } \\
\hline Gomi et al. (2007) [53] & 3 days before full-mouth $\mathrm{SRP}^{\mathrm{a}}$ & $500-500-500$ & Diarrhoea \\
\hline Haffajee et al. (2007) [48] & $\begin{array}{l}\text { First session of quadrant-wise SRP } \\
\text { in weekly visits }\end{array}$ & $500-500-500$ & $\begin{array}{l}\text { Allergic reaction to AZM, difficulties } \\
\text { swallowing the tablets }\end{array}$ \\
\hline Han et al. (2012) [54] & $\begin{array}{l}\text { Last session of quadrant-wise SRP } \\
\text { in sequential sessions within } \\
4 \text { weeks }\end{array}$ & $500-500-500$ & None \\
\hline Mascarenhas et al. (2005) [51] & $\begin{array}{l}\text { End of last SRP session of } 2 \text { sessions } \\
\text { within } 1 \text { week }^{\mathrm{b}}\end{array}$ & $500-250-250-250-250$ & n.r. \\
\hline Oteo et al. (2010) [50] & $\begin{array}{l}\text { End of last SRP session of } 2 \text { sessions } \\
\text { within } 1 \text { week }\end{array}$ & $500-500-500$ & Diarrhoea \\
\hline Sampaio et al. (2011) [55] & $\begin{array}{l}\text { End of last session, SRP in 4-6 } \\
\text { sessions in } 2 \text { weeks }\end{array}$ & $500-500-500-500-500$ & $\begin{array}{l}\text { Diarrhoea }(2 \mathrm{x}) \text {, headache and dizziness } \\
(1 \mathrm{x}) \text {, excessive sleepiness }(3 \mathrm{x}) \text {, metallic } \\
\text { taste }(2 \mathrm{x}) \text {, general unwellness }(1 \mathrm{x})\end{array}$ \\
\hline Yashima et al. $(2009)^{\mathrm{c}}[49]$ & $\begin{array}{l}3 \text { days before full-mouth SRP } \\
3 \text { days before SRP in } 3 \text { sessions } \\
\text { within } 1 \text { week }\end{array}$ & $500-500-500$ & Diarrhoea \\
\hline \multicolumn{4}{|l|}{ Aggressive periodontitis } \\
\hline Emingil et al. (2012) [52] & $\begin{array}{l}\text { End of last session of quadrant-wise } \\
\text { SRP within } 3 \text { weeks }\end{array}$ & $500-500-500$ & None \\
\hline Haas et al. (2008) [47] & $\begin{array}{l}\text { First session of quadrant- or sextant- } \\
\text { wise SRP within } 2 \text { weeks }\end{array}$ & $500-500-500$ & None \\
\hline
\end{tabular}

SRP scaling and root planing, n.r. not reported

${ }^{\text {a }}$ Control group: SRP in 4-6 sessions with 1-week intervals

${ }^{\mathrm{b}} \mathrm{SRP}$ within 1-2 weeks

${ }^{\mathrm{c}}$ Control group: SRP in six sessions within 6 weeks

the control received SRP only [48]. From this study [48], only the intervention with AZM and the control were used for comparison in the current review.

\section{Outcomes}

Chronic periodontitis Data on tooth loss as an outcome were reported by one study [48]. While no teeth were lost in the control group, two teeth were extracted in the AZM group during the course of the study.

Five out of seven studies investigating $\mathrm{ChP}$ documented a beneficial effect of systemically administered AZM compared to SRP in terms of the PD measures applied [48-51, 53] (Table 1). One study reported a significant lower mean PD after 6 months compared to the control group [53]. A significantly higher PD reduction in the test group after 6 months was shown in one study [50]. Two publications described significant differences in PD change between test and control groups at 6 and 12 months [48, 49]. No beneficial effect of AZM was found in two studies [54, 55] (Table 1).

In three of the seven studies on $\mathrm{ChP}$, the changes in $\mathrm{CAL}$ differed significantly between test and control groups after 6 months [50] or 12 months [48, 49]. No significant differences in CAL measures were described in three studies [53-55] (Table 2).
One study reported conflicting results on the outcome in smokers with ChP [51]. A significant mean change in perpatient PD was described in moderate and deep sites as well as in mean per-patient CAL in deep sites, when adjunctive AZM was applied. No significant changes were found in mean changes in per-patient PD and CAL in shallow sites or in mean changes in per-patient CAL in moderate sites or percentages of sites with CAL loss $\geq 2 \mathrm{~mm}$ (Tables 1 and 2).

Aggressive periodontitis From the two studies investigating treatment in patients with AgP, one reported a positive effect of AZM revealing a significantly higher percentage of teeth with a PD decrease of $\geq 2 \mathrm{~mm}$ in the test group. With respect to deep sites ( $P D \geq 7 \mathrm{~mm}$ ), there was, however, no significant difference in mean PD change after 12 months [47] (Table 1). Emingil et al. [52] detected no significant difference in PD measures between the test and placebo group after 6 months [52] (Table 1).

CAL changes differed significantly between test and control in sites with $\mathrm{CAL} \geq 4 \mathrm{~mm}$ and in the percentage of teeth with CAL increase of $\geq 1 \mathrm{~mm}$ [47]. Neither the percentage of teeth with CAL decrease $\geq 2 \mathrm{~mm}$ nor the sites with CAL 4-6 and $\geq 7 \mathrm{~mm}$ revealed any difference between test and control $[47,52]$ (Table 2). 
Fig. 1 Selection process for the studies included (from [42]; for more information, visit www. prisma-statement.org)

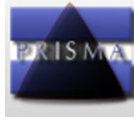

PRISMA 2009 Flow Diagram

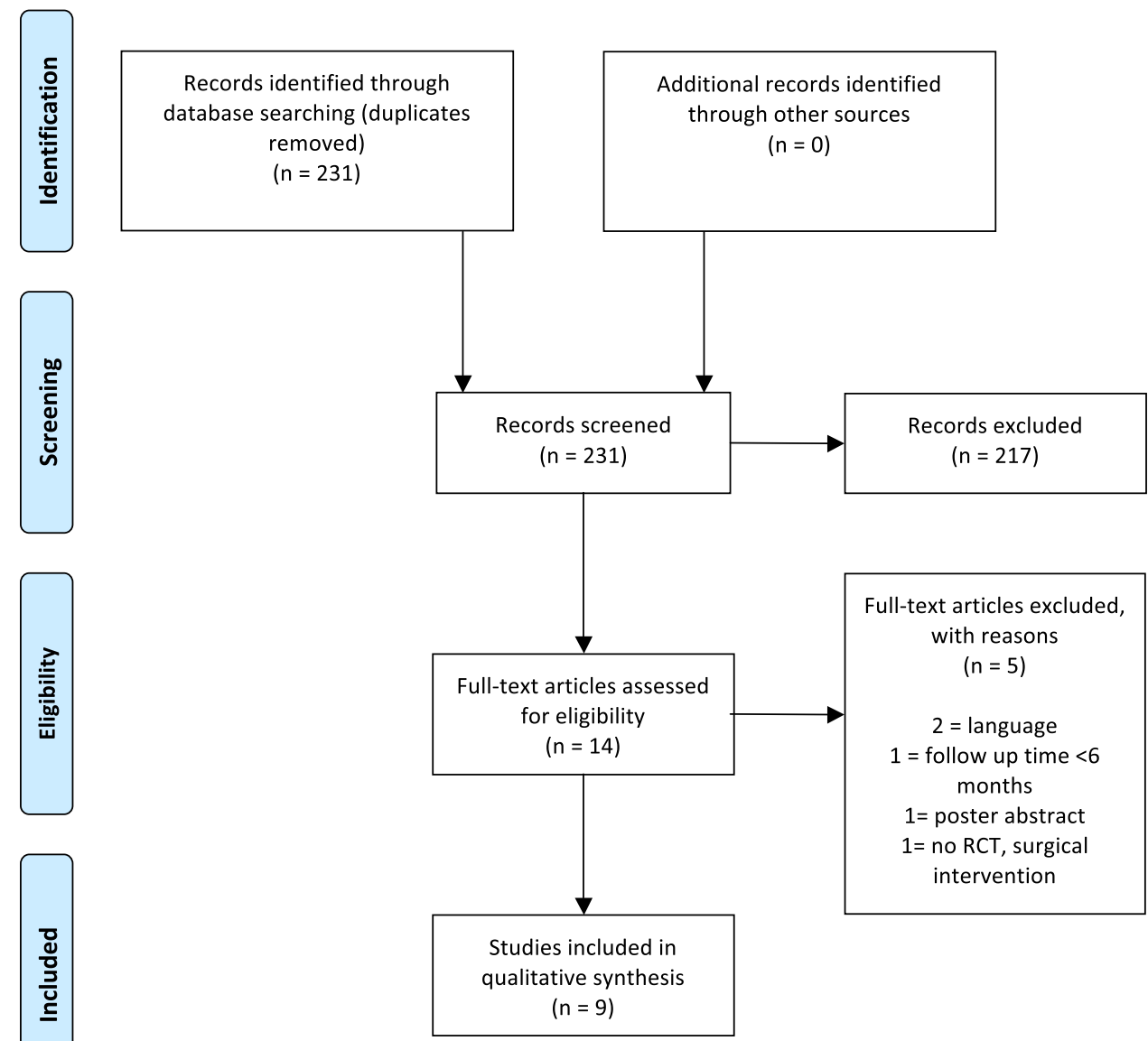

Adverse events Minor adverse events were reported in five studies such as gastrointestinal reactions (e.g. diarrhoea, metallic taste) $[49,50,53,55]$ or peripheral nervous system reactions (e.g. headache and dizziness) [55]. One study described an allergic reaction [48], but no information on extent or severity was described. None of the included studies reported on major adverse events.

\section{Discussion}

The aim of this systematic review was to explore the effect and to discuss the relevant parameters for effect modification of systemically administered AZM on non-surgical periodontal therapy with SRP. The nine RCTs included differed in terms of study population, sample size, risk of bias, statistical methods applied, primary outcome, administration of placebo, start of medication and dosage of AZM and/or sequencing of non-surgical treatment. The pronounced heterogeneity among the studies led to a synthesis of results using a vote counting method applied for the secondary outcome parameters, PD and CAL, while prohibiting a conventional statistical metaanalysis. In addition, the methodological quality of included studies revealed a relative low risk of bias in the majority of included studies (Appendix 2). Keeping these issues in mind, five (PD) and four (CAL) out of seven studies revealed a beneficial effect of AZM for the clinical relevant parameters, $\mathrm{PD}$ and $\mathrm{CAL}$, in ChP patients. The two studies describing the outcome in AgP patients documented conflicting results in terms of beneficial effects of AZM as an adjunct to SRP.

Recent reviews indicate significant benefits of several systemic antibiotics, including AZM, in non-surgical treatment of chronic and/or aggressive periodontitis [3-5]. Herrera et al. [3] reviewed a number of RCTs administering local and systemic antibiotics, including two of the seven studies on $\mathrm{ChP}$ assessed in this analysis [3]. A broad analysis with a metaanalysis of data from several antibiotic agents, dosage and administration regimes on the effects of systemic antibiotics 
in non-surgical periodontitis treatment was performed by Keestra et al. [4, 5]. Our review analyzed the clinical effects from RCTs using systemically administered AZM compared to SRP without adjunctive antibiotic. This approach allowed the observation of differential effects of AZM in the light of mode and/or time point of application (see below). Particularly, the use of adjunctive systemic antibiotics in non-surgical treatment of $\mathrm{AgP}$ is well established [4, 11-14]. In our review, only two studies reported on $\mathrm{AgP}$ patients and demonstrated conflicting results. While Emingil et al. [52] did not report beneficial effects of AZM, Haas et al. [47] demonstrated a higher change in mean PD in sites with moderate PD (4$6 \mathrm{~mm}$ ), but not in sites with severe PD of $\geq 7 \mathrm{~mm}$. These limited data, however, prohibit stating a reliable conclusion to $\mathrm{AgP}$ patients.

The included studies applied different treatment protocols for SRP, i.e. SRP in two to six sessions within 1 to 4 weeks [47-52, 54, 55] or full-mouth SRP [49, 53]. However, in terms of $\mathrm{PD}$ reduction, the sequences used may be comparable when SRP is applied without systemic antibiotics $[56,57]$ or in conjunction with AZM [49]. With respect to the possible positive adjunctive effect of AZM, the studies included did not reveal a superiority of any treatment protocol (Tables 1, 2 and 3). In other words, the ideal therapeutic sequencing of SRP with maximal effects of AZM needs to be identified in further RCTs.

The seven studies on ChP applied AZM with $500 \mathrm{mg}$ once daily for 3 days [48-50, 53, 54] to 5 days [55] or applied $500 \mathrm{mg}$ on the $1 \mathrm{st}$ day, followed by $250 \mathrm{mg}$ for four further days [51]. An extended period of AZM intake was not associated with a beneficial effect of AZM in comparison to control, while several adverse events, including diarrhoea and sleepiness, were reported by the test group in one study [55].

Minor adverse events were present in five of the nine studies included. In contrast to the combination of amoxicillin and metronidazole, AZM intake is regarded to have very low occurrence of adverse events [58]. However, as mentioned in the "Introduction", a possible cardiovascular risk [31] of AZM intake was raised in the literature. While there are some reports available describing these severe complications, a recent meta-analysis comprising data from 12 RCTs found no increased risks for mortality or for cardiovascular events associated with azithromycin therapy compared with placebo [59]. When AZM is selected as an antibiotic drug in periodontitis therapy particularly in patients with a cardiovascular history, the consultation of the patient's physician is advisable.

As described earlier, the duration of antibiotic intake may have an impact on adherence to the administration protocol. Compared to the standard $[1,2]$ with amoxicillin and metronidazole administered for at least 7 days, the use of AZM facilitated a shorter and lower dosage regime, which may have the potential to improve patient compliance. A short administration period of only 3 days was recently presented also for the combination of amoxicillin and metronidazole [23].

Further variations were observed in the studies included regarding the start of antibiotic intake. All studies administering AZM 3 days before or at the first SRP visit documented a beneficial effect of AZM [48, 49, 53]. In contrast, among the four studies prescribing AZM at the last session of SRP [50, $51,54,55]$, only two reported a beneficial effect of AZM [50, 51]. This observation might be explained by the pharmacological properties of AZM, particularly the uptake in phagocytic cells and the slow release from these cells $[37-39,60]$. Evidence from an analysis of brain tissues indicates an increase of the AZM concentration from the 1st to the 2nd day of intake [61]. For periodontal tissues and gingival crevicular fluid, an elevated concentration of AZM was shown $[62,63]$. Therefore, an administration before or at the start of the therapy seems to facilitate a maximum and/or sufficiently high AZM concentration during the performance of SRP [48, 49, 53]. Given the observations from this systematic analysis of RCTs, the treatment regime for adjunctive AZM differs markedly from the protocol for adjunctive amoxicillin and metronidazole. It has been suggested that the combination of amoxicillin and metronidazole "should start on the day of debridement completion", when the biofilm in all affected periodontia is disrupted, i.e. in the case of quadrant-wise SRP after instrumentation of the last quadrant and in the case of fullmouth scaling before the SRP on the same day [2].

A distinction between the outcomes in sites with different PD was given in five studies [47, 50-52, 55]. Certainly, the outcome after SRP of deeper PD is more critical due to the limitations of non-surgical mechanical debridement particularly in multi-rooted teeth [64-66]. Since a residual PD of $>5 \mathrm{~mm}$ after active treatment is at risk for ongoing attachment loss [67], the number of sites with PD above that threshold is of focused interest in order to have an estimate of sites in need for further (surgical) treatment. Recently, the potential of the combination of amoxicillin and metronidazole for the avoidance of surgical therapy was shown [21].

The healing time allowed to elapse after non-surgical periodontal treatment is of utmost importance for decisionmaking at a reasonable time point. Evidence shows a marked reduction of PD after SRP after 3 months [68]. However, in initially deep sites, wound healing seems to require more than 3 months [68]. In the current review, only studies with at least 6-month observation period were included to account for the healing time required after non-surgical periodontal therapy. Any longer observation periods are challenging and potentially assess the additional influence of the supportive periodontal treatment and not only the effect of the initial active treatment.

Tobacco consumption is known to have a negative influence on periodontitis progression and treatment outcome [69]. 
A beneficial effect of adjunctive amoxicillin and metronidazole in non-surgical therapy of tobacco-associated periodontal disease has been described [18]. While one study defined smoking broadly as $>10$ cigarettes a day and non-smoking as non-smoker, former smoker or zero-to-nine cigarettes a day [50], two publications excluded subjects smoking $\geq 10$ cigarettes a day $[52,54]$. Detailed data on tobacco consumption of the patients were missing in four trials [47, 48, 53, 55]. Mascarenhas et al. [51] included only smokers, and Yashima et al. [49] included solely non-smoking participants. Smoking was considered as a confounding factor in the statistical analyses in two studies $[47,50]$. Therefore, the distinctive effect of adjunctive AZM in smokers' periodontitis could not be explored sufficiently. Since periodontal surgery in smokers needs to be carefully considered due to an increased risk of complications, further research focusing on this clinically relevant and highly prevalent population of periodontitis patients is indicated [69].

The studies included in the current review revealed some variability related to demographic data and study designs. The number of subjects in the majority of studies ranged between 24 and 40, while one study reported on 92 patients allocated to three treatment groups and one control [48]. Although, in most studies, the number of included patients was justified by preceding power calculations [47, 48, 50, 52, 54, 55], one has to be aware that a sample size is strongly related to study quality and risk of bias [70]. Study origin is another factor, which has to be accounted for when interpreting standard of care in conjunction to socioeconomic status, outcomes from antibiotic administration or prevalence of bacterial resistance to antibiotics $[28,29]$.

\section{Conclusion}

In summary, several studies in different populations have explored a possible beneficial effect of the adjunctive use of $\mathrm{AZM}$ on periodontal non-surgical treatment of $\mathrm{ChP}$ or $\mathrm{AgP}$ patients. For the therapy of both diseases, there are, however, no data available on the superiority of AZM against the standard antibiotic combination of metronidazole and amoxicillin. According to the limited external evidence available in this systematically performed analysis, AZM may therefore be very carefully regarded as a potential alternative antibiotic systemic drug in selected cases of $\mathrm{ChP}$, particularly when contraindications for the standard protocol involving adjunctive amoxicillin and metronidazole are given.

\section{Direction for further research}

The consideration of the following parameters is suggested for future research:
1. Further evaluation of systemic AZM as an adjunct to SRP (in non-smokers and in patients with smokers' periodontitis)

2. Comparison of adjunctive systemic AZM to adjunctive amoxicillin and metronidazole in non-surgical SRP

3. Evaluation of the optimal SRP sequencing, when adjunctive systemic AZM is applied

4. Further investigation of the optimal starting point of the systemic AZM medication

5. Focus on clinically relevant outcome parameters such as on distinguished PD sites (moderate/deep)

6. Adequate sample size and observation times ( $\geq 6$ months).

Acknowledgments Parts of this research were conducted by S. L. Buset in partial fulfilment of the requirements for an MD degree from the University of Basel, Switzerland.

Conflict of interest The authors declare that they have no conflict of interests.

\section{References}

1. Haffajee AD, Socransky SS, Gunsolley JC (2003) Systemic antiinfective periodontal therapy. A systematic review. Ann Periodontol 8:115-181

2. Herrera D, Alonso B, Leon R, Roldan S, Sanz M (2008) Antimicrobial therapy in periodontitis: the use of systemic antimicrobials against the subgingival biofilm. J Clin Periodontol 35:4566

3. Herrera D, Matesanz P, Bascones-Martinez A, Sanz M (2012) Local and systemic antimicrobial therapy in periodontics. J Evid Based Dent Pract 12:50-60

4. Keestra JA, Grosjean I, Coucke W, Quirynen M, Teughels W (2014) Non-surgical periodontal therapy with systemic antibiotics in patients with untreated aggressive periodontitis: a systematic review and meta-analysis. J Periodontal Res. doi:10.1111/jre.12252

5. Keestra JA, Grosjean I, Coucke W, Quirynen M, Teughels W (2014) Non-surgical periodontal therapy with systemic antibiotics in patients with untreated chronic periodontitis: a systematic review and meta-analysis. J Periodontal Res. doi:10.1111/jre.12221

6. Astasov-Frauenhoffer M, Braissant O, Hauser-Gerspach I, Weiger R, Walter C, Zitzmann NU, Waltimo T (2014) Microcalorimetric determination of the effects of amoxicillin, metronidazole, and their combination on in vitro biofilm. J Periodontol 85:349-357

7. Kulik Kunz EM, Lenkeit K, Waltimo T, Weiger R, Walter C (2014) Combinatorial effects of amoxicillin and metronidazole on selected periodontal bacteria and whole plaque samples. Arch Oral Biol 59: 608-615

8. Walter C, Kulik EM, Weiger R, Zitzmann NU, Waltimo T (2011) Additive or synergistic antimicrobial effects of amoxicillin and metronidazole on whole plaque samples: a preliminary report. J Int Acad Periodontol 13:11-16

9. Pavicic MJ, van Winkelhoff AJ, Douque NH, Steures RW, de Graaff J (1994) Microbiological and clinical effects of metronidazole and amoxicillin in Actinobacillus actinomycetemcomitansassociated periodontitis. A 2-year evaluation. J Clin Periodontol 21:107-112

10. Pavicic MJ, van Winkelhoff AJ, Pavicic-Temming YA, de Graaff J (1994) Amoxycillin causes an enhanced uptake of metronidazole in 
Actinobacillus actinomycetemcomitans: a mechanism of synergy. J Antimicrob Chemother 34:1047-1050

11. Guerrero A, Griffiths GS, Nibali L, Suvan J, Moles DR, Laurell L, Tonetti MS (2005) Adjunctive benefits of systemic amoxicillin and metronidazole in non-surgical treatment of generalized aggressive periodontitis: a randomized placebo-controlled clinical trial. J Clin Periodontol 32:1096-1107

12. Kaner D, Bernimoulin JP, Hopfenmuller W, Kleber BM, Friedmann A (2007) Controlled-delivery chlorhexidine chip versus amoxicillin/metronidazole as adjunctive antimicrobial therapy for generalized aggressive periodontitis: a randomized controlled clinical trial. J Clin Periodontol 34:880-891

13. Rodrigues AS, Lourencao DS, Lima Neto LG, Pannuti CM, Hirata RD, Hirata MH, Lotufo RF, De Micheli G (2012) Clinical and microbiologic evaluation, by real-time polymerase chain reaction, of non-surgical treatment of aggressive periodontitis associated with amoxicillin and metronidazole. J Periodontol 83:744-752

14. Xajigeorgiou C, Sakellari D, Slini T, Baka A, Konstantinidis A (2006) Clinical and microbiological effects of different antimicrobials on generalized aggressive periodontitis. J Clin Periodontol 33: 254-264

15. Cionca N, Giannopoulou C, Ugolotti G, Mombelli A (2010) Microbiologic testing and outcomes of full-mouth scaling and root planing with or without amoxicillin/metronidazole in chronic periodontitis. J Periodontol 81:15-23

16. Feres M, Soares GM, Mendes JA, Silva MP, Faveri M, Teles R, Socransky SS, Figueiredo LC (2012) Metronidazole alone or with amoxicillin as adjuncts to non-surgical treatment of chronic periodontitis: a 1-year double-blinded, placebo-controlled, randomized clinical trial. J Clin Periodontol 39:1149-1158

17. Albandar JM (2012) Adjunctive antibiotics with nonsurgical periodontal therapy improve the clinical outcome of chronic periodontitis in current smokers. J Evid Based Dent Pract 12:63-66

18. Matarazzo F, Figueiredo LC, Cruz SE, Faveri M, Feres M (2008) Clinical and microbiological benefits of systemic metronidazole and amoxicillin in the treatment of smokers with chronic periodontitis: a randomized placebo-controlled study. J Clin Periodontol 35: 885-896

19. Schmidt JC, Walter C, Rischewski JR, Weiger R (2013) Treatment of periodontitis as a manifestation of neutropenia with or without systemic antibiotics: a systematic review. Pediatr Dent 35:E54-63

20. Walter C, Buset S, Thillainathan L, Weiger R, Zitzmann NU (2013) Evaluation of periodontal therapy in undergraduate courses of the University of Basle. A retrospective study. Schweiz Monatsschr Zahnmed 123:861-877

21. Mombelli A, Cionca N, Almaghlouth A (2011) Does adjunctive antimicrobial therapy reduce the perceived need for periodontal surgery? Periodontol 2000 55:205-216

22. van Winkelhoff AJ, Rodenburg JP, Goene RJ, Abbas F, Winkel EG, de Graaff J (1989) Metronidazole plus amoxycillin in the treatment of Actinobacillus actinomycetemcomitans associated periodontitis. J Clin Periodontol 16:128-131

23. Cosgarea J, Juncar R, Tristiu R, Arweiler N, Heumann C, Lascu L, Sculean A (2014) Nicht - chirurgische parodontale Therapie mit adjunktiver Gabe von Amoxicillin und Metronidazol für unterschiedliche Zeitabstände in Patienten mit schwerer chronischer Parodontitis. Parodontologie 23:344-345

24. Moreira RM, Feres-Filho EJ (2007) Comparison between fullmouth scaling and root planing and quadrant-wise basic therapy of aggressive periodontitis: 6-month clinical results. J Periodontol 78:1683-1688

25. Silva-Senem MX, Heller D, Varela VM, Torres MC, Feres-Filho EJ, Colombo AP (2013) Clinical and microbiological effects of systemic antimicrobials combined to an anti-infective mechanical debridement for the management of aggressive periodontitis: a 12month randomized controlled trial. J Clin Periodontol 40:242-251
26. Lopez NJ, Socransky SS, Da Silva I, Japlit MR, Haffajee AD (2006) Effects of metronidazole plus amoxicillin as the only therapy on the microbiological and clinical parameters of untreated chronic periodontitis. J Clin Periodontol 33:648-660

27. Mombelli A (2005) Antimicrobial profiles of periodontal pathogens and systemic antimicrobial therapy. J Clin Periodontol 32:891-892

28. van Winkelhoff AJ, Herrera D, Oteo A, Sanz M (2005) Antimicrobial profiles of periodontal pathogens isolated from periodontitis patients in The Netherlands and Spain. J Clin Periodontol 32:893-898

29. Walter C, Weiger R (2006) Antibiotics as the only therapy of untreated chronic periodontitis: a critical commentary. J Clin Periodontol 33:938-939, author reply 940-1

30. Rams TE, Feik D, Mortensen JE, Degener JE, van Winkelhoff AJ (2014) Antibiotic susceptibility of periodontal Streptococcus constellatus and Streptococcus intermedius clinical isolates. J Periodontol 85:1792-1798

31. Ray WA, Murray KT, Hall K, Arbogast PG, Stein CM (2012) Azithromycin and the risk of cardiovascular death. N Engl J Med 366:1881-1890

32. WHO (2014) Antibiotic resistance: global report on surveillance. ISBN: 9789241564748

33. Sgolastra F, Gatto R, Petrucci A, Monaco A (2012) Effectiveness of systemic amoxicillin/metronidazole as adjunctive therapy to scaling and root planing in the treatment of chronic periodontitis: a systematic review and meta-analysis. J Periodontol 83:1257-1269

34. Guerrero A, Echeverria JJ, Tonetti MS (2007) Incomplete adherence to an adjunctive systemic antibiotic regimen decreases clinical outcomes in generalized aggressive periodontitis patients: a pilot retrospective study. J Clin Periodontol 34:897-902

35. Llor C, Sierra N, Hernandez S, Moragas A, Hernandez M, Bayona C, Miravitlles M (2009) The higher the number of daily doses of antibiotic treatment in lower respiratory tract infection the worse the compliance. J Antimicrob Chemother 63:396-399

36. Muniz FW, de Oliveira CC, de Sousa arvalho CR, Moreira MM, de Moraes ME, Martins RS (2013) Azithromycin: a new concept in adjuvant treatment of periodontitis. Eur J Pharmacol 705:135-139

37. Bartold PM, du Bois AH, Gannon S, Haynes DR, Hirsch RS (2013) Antibacterial and immunomodulatory properties of azithromycin treatment implications for periodontitis. Inflammopharmacology 21:321-238

38. Hand WL, Hand DL (2001) Characteristics and mechanisms of azithromycin accumulation and efflux in human polymorphonuclear leukocytes. Int J Antimicrob Agents 18:419-425

39. McDonald PJ, Pruul H (1991) Phagocyte uptake and transport of azithromycin. Eur J Clin Microbiol Infect Dis 10:828-833

40. Wildfeuer A, Laufen H, Zimmermann T (1994) Distribution of orally administered azithromycin in various blood compartments. Int J Clin Pharmacol Ther 32:356-360

41. Liberati A, Altman DG, Tetzlaff J, Mulrow C, Gotzsche PC, Ioannidis JP, Clarke M, Devereaux PJ, Kleijnen J, Moher D (2009) The PRISMA statement for reporting systematic reviews and meta-analyses of studies that evaluate health care interventions: explanation and elaboration. J Clin Epidemiol 62:e1-34

42. Moher D, Liberati A, Tetzlaff J, Altman DG, The PRISMA Group (2009) Preferred reporting items for systematic reviews and metaanalyses: the PRISMA statement. PLoS Med 6(6): e1000097. doi: 10.1371/journal.pmed1000097.

43. Hopkins S (1991) Clinical toleration and safety of azithromycin Am J Med 91:40S-45S

44. Martinez MA, Vuppalanchi R, Fontana RJ, Stolz A, Kleiner DE, Hayashi PH, Gu J, Hoofnagle JH, Chalasani N (2014) Clinical and histologic features of azithromycin-induced liver injury. Clin Gastroenterol Hepatol. doi:10.1016/j.cgh.2014.07.054

45. Higgins JP, Altman DG, Gotzsche PC, Juni P, Moher D, Oxman AD, Savovic J, Schulz KF, Weeks L, Sterne JA (2011) The 
Cochrane Collaboration's tool for assessing risk of bias in randomised trials. BMJ 343:d5928

46. Graziani F, Figuero E, Herrera D (2012) Systematic review of quality of reporting, outcome measurements and methods to study efficacy of preventive and therapeutic approaches to peri-implant diseases. J Clin Periodontol 39(Suppl 12):224-244

47. Haas AN, de Castro GD, Moreno T, Susin C, Albandar JM, Oppermann RV, Rosing CK (2008) Azithromycin as an adjunctive treatment of aggressive periodontitis: 12-months randomized clinical trial. J Clin Periodontol 35:696-704

48. Haffajee AD, Torresyap G, Socransky SS (2007) Clinical changes following four different periodontal therapies for the treatment of chronic periodontitis: 1-year results. J Clin Periodontol 34:243-253

49. Yashima A, Gomi K, Maeda N, Arai T (2009) One-stage full-mouth versus partial-mouth scaling and root planing during the effective half-life of systemically administered azithromycin. J Periodontol 80:1406-1413

50. Oteo A, Herrera D, Figuero E, O'Connor A, Gonzalez I, Sanz M (2010) Azithromycin as an adjunct to scaling and root planing in the treatment of Porphyromonas gingivalis-associated periodontitis: a pilot study. J Clin Periodontol 37:1005-1015

51. Mascarenhas P, Gapski R, Al-Shammari K, Hill R, Soehren S, Fenno JC, Giannobile WV, Wang HL (2005) Clinical response of azithromycin as an adjunct to non-surgical periodontal therapy in smokers. J Periodontol 76:426-436

52. Emingil G, Han B, Ozdemir G, Tervahartiala T, Vural C, Atilla G, Baylas H, Sorsa T (2012) Effect of azithromycin, as an adjunct to nonsurgical periodontal treatment, on microbiological parameters and gingival crevicular fluid biomarkers in generalized aggressive periodontitis. J Periodontal Res 47:729-739

53. Gomi K, Yashima A, Nagano T, Kanazashi M, Maeda N, Arai T (2007) Effects of full-mouth scaling and root planing in conjunction with systemically administered azithromycin. J Periodontol 78: 422-429

54. Han B, Emingil G, Ozdemir G, Tervahartiala T, Vural C, Atilla G, Baylas H, Sorsa T (2012) Azithromycin as an adjunctive treatment of generalized severe chronic periodontitis: clinical, microbiologic, and biochemical parameters. J Periodontol 83:1480-1491

55. Sampaio E, Rocha M, Figueiredo LC, Faveri M, Duarte PM, Gomes Lira EA, Feres M (2011) Clinical and microbiological effects of azithromycin in the treatment of generalized chronic periodontitis: a randomized placebo-controlled clinical trial. J Clin Periodontol 38:838-846

56. Farman M, Joshi RI (2008) Full-mouth treatment versus quadrant root surface debridement in the treatment of chronic periodontitis: a systematic review. Br Dent J 205, E18, discussion 496-497
57. Matthews DC (2009) No difference between full-mouth and quadrant-wise treatment of chronic periodontitis. Evid Based Dent 10:17

58. Principi N, Esposito S (1999) Comparative tolerability of erythromycin and newer macrolide antibacterials in paediatric patients. Drug Saf 20:25-41

59. Almalki ZS, Guo JJ (2014) Cardiovascular events and safety outcomes associated with azithromycin therapy: a meta-analysis of randomized controlled trials. Am Health Drug Benefits 7:318-328

60. Panteix G, Guillaumond B, Harf R, Desbos A, Sapin V, Leclercq M, Perrin-Fayolle M (1993) In-vitro concentration of azithromycin in human phagocytic cells. J Antimicrob Chemother 31(Suppl E): $1-4$

61. Jaruratanasirikul S, Hortiwakul R, Tantisarasart T, Phuenpathom N, Tussanasunthornwong S (1996) Distribution of azithromycin into brain tissue, cerebrospinal fluid, and aqueous humor of the eye. Antimicrob Agents Chemother 40:825-826

62. Gomi K, Yashima A, Iino F, Kanazashi M, Nagano T, Shibukawa N, Ohshima T, Maeda N, Arai T (2007) Drug concentration in inflamed periodontal tissues after systemically administered azithromycin. J Periodontol 78:918-923

63. Malizia T, Tejada MR, Ghelardi E, Senesi S, Gabriele M, Giuca MR, Blandizzi C, Danesi R, Campa M, Del Tacca M (1997) Periodontal tissue disposition of azithromycin. J Periodontol 68: 1206-1209

64. Loos B, Nylund K, Claffey N, Egelberg J (1989) Clinical effects of root debridement in molar and non-molar teeth. A 2-year follow-up. J Clin Periodontol 16:498-504

65. Nordland P, Garrett S, Kiger R, Vanooteghem R, Hutchens LH, Egelberg J (1987) The effect of plaque control and root debridement in molar teeth. J Clin Periodontol 14:231-236

66. Walter C, Weiger R, Zitzmann NU (2011) Periodontal surgery in furcation-involved maxillary molars revisited - an introduction of guidelines for comprehensive treatment. Clin Oral Investig 15:9-20

67. Matuliene G, Pjetursson BE, Salvi GE, Schmidlin K, Bragger U, Zwahlen M, Lang NP (2008) Influence of residual pockets on progression of periodontitis and tooth loss: results after 11 years of maintenance. J Clin Periodontol 35:685-695

68. Badersten A, Nilveus R, Egelberg J (1984) Effect of nonsurgical periodontal therapy. II. Severely advanced periodontitis. J Clin Periodontol 11:63-76

69. Warnakulasuriya S, Dietrich T, Bornstein MM, Casals Peidro E, Preshaw PM, Walter C, Wennstrom JL, Bergstrom J (2010) Oral health risks of tobacco use and effects of cessation. Int Dent J 60:730

70. Michalowicz BS, Gustafsson A, Thumbigere-Math V, Buhlin K (2013) The effects of periodontal treatment on pregnancy outcomes. J Clin Periodontol 40(Suppl 14):S195-208 